
Motrivivência
v. 28,
n. 47
p. 47-66, maio/2016

\title{
A EDUCAÇÃO FÍSICA COMO TERRITÓRIO DE DEMARCAÇÃO DOS GÊNEROS POSSÍVEIS: vivências escolares de pessoas travestis, transexuais e transgêneros
}

Neil Franco

\section{RESUMO}

A Educação Física escolar interpretada através das vivências de pessoas que ultrapassam e/ou vivem nas fronteiras do gênero é o foco deste estudo. Destaca reflexões desencadeadas pelas análises do folder "A travesti e o[/a] educador[/a]" - sobre a inserção desses sujeitos na aula de Educação Física, correlacionado a fontes bibliográficas, entrevistas realizadas e questionários aplicados a professoras travestis, transexuais e transgêneros brasileiras. Concluiu-se que, não diferente da escola como um todo, a Educação Física é também um espaço que exalta a incoerência entre a realidade do cotidiano educacional e as normativas que determinam a escola como gestora da inclusão.

Palavras-chave: Professoras Trans; Transfobia; Educação Física; Gênero

1 Doutor em Educação. Professor adjunto da Faculdade de Educação Física da UFJF. Juiz de Fora/Minas Gerais, Brasil. E-mail: neilfranco010@hotmail.com 


\section{INTRODUÇÃO}

Desde sua criação, ocupando um lugar representativo como instituição social, a escola tem como objetivo o ensino, a aprendizagem e a manutenção dos diversos conhecimentos que constituem a sociedade em que ela está inserida. Este processo se efetiva por meio da Educação de homens e mulheres estabelecendo as diretrizes que os/as situam histórica, social e culturalmente como seres humanos. Neste contexto de inserção, a distinção, a diferença e a incompletude são as marcas primordiais do ser humano, dimensões essas que o inserem no mundo pela via de seu corpo.

Pensar no corpo como instrumento de construção do sujeito nos remete à definição de corpo elaborada por Silvana Goellner (2003), para quem "um corpo não é apenas um corpo, é também o seu entorno", que ultrapassa a concepção estritamente biológica de se constituir de um conjunto de músculos, ossos, vísceras, reflexos e sensações. O corpo se define pelos significados sociais e culturais que a ele se inserem.

O corpo é também a roupa e os acessórios que o adornam, as intervenções que nele se operam, a imagem que dele se produz, as máquinas que nele se acoplam, os sentidos que nele se incorporam, os silêncios que por ele falam, os vestígios que nele se exibem, a educação de seus gestos... enfim, é um sem limite de possibilidades sempre reinventadas e a serem descobertas (GOELLNER, 2003, p. 29).

(Re)inventar, (re)significar, ou, literalmente, (re)construir o que a cultura e a vida social elaboraram pautadas nas certezas que definiram o ser humano nos conduzem a interpretar o corpo como um espaço de reencontros e, concomitantemente, um território de afrontamentos das verdades que ao longo da história fizeram do corpo uma dimensão fixa e estável, ou, como observou Judith Butler (2003), "simplesmente matéria". Para ela, o corpo é uma estrutura imaginada consequência/produto/efeito do desejo e não a causa deste, portanto, constituído e delineado pelo discurso e pela lei estabelecendo relações estreitas com as dimensões que o integram, sejam elas, de gênero, sexual, de raça e etnia, geracional, de classe social e, também, da própria estrutura corporal e psíquica; aspectos que em decorrências dos padrões sociais e culturais podem situar o sujeito como integrante ou não da condição humana.

Neste sentido, a forma como o sujeito adquire ou constrói suas relações com essas dimensões na efetivação de seu corpo pode situá-lo fora da condição humana hegemonicamente instituída e inspirada na concepção de sujeito moderno que se consagra nos princípios iluministas, sendo esse sujeito uma invenção e não uma descoberta da modernidade. Portanto, como descrevem Alfredo Veiga-Neto e Carlos Nogueira (2010), essa invenção pauta-se exclusivamente a partir dos princípios constituintes da identidade social de seus "arquitetos": brancos, machos, eurocêntricos, colonialistas, burgueses, cristãos, ilustrados e heterossexuais. Essas marcas definiram a possibilidade de um modelo de sujeito que habitaria um mundo necessariamente natural e universal.

A inadequação de certos sujeitos a esses princípios definidores do padrão de humanidade por serem negros/as, pobres, mulheres, homossexuais, travestis, transexuais, transgêneros, deficientes, e tantas 
outras formas de demarcadores identitários incidem sobre esses sujeitos as formas mais acirradas de desprezo social, em que a escola historicamente consolida-se como um dos principais vetores desses processos de exclusão. Em contraposição a esse processo, a perspectiva da inclusão tornou-se pauta necessária no contexto social com implicações específicas para o contexto escolar.

Isabel Sanches e Antônio Teodoro (2006) destacam a inclusão como a palavra que hoje pretende definir igualdade, fraternidade, direitos humanos ou democracia, mas que se torna mais complexa quando aplicada na realidade prática. Para o campo educacional, sua origem fundamenta-se no centro das pessoas em situação de deficiência, inserindo-se, contudo, também nos grandes movimentos contra a exclusão social, como é o caso da emancipação feminina, sob o princípio da defesa da justiça social e da diversidade humana. Com isso, a inclusão escolar parece conceitualmente voltar-se para as questões de discentes em situação de deficiência, o que é uma percepção equivocada, pois ela destina-se ao alunado com necessidades educativas. Isso se refere a proposta de um novo olhar sobre a sociedade em que a justiça, o respeito e a equidade sejam os grandes princípios norteadores da Educação, assim como decretado na assinatura da Declaração de Salamanca em 1994 (SANCHES; TEODORO, 2006).

Neste sentido, essa Educação inclusiva deve/deveria processar em escolas regulares propiciando meios de combater atitudes discriminatórias, criando comunidades abertas e solidárias, com o propósito de efetivar a "Educação para todos/as", independente do sexo, gênero, cor, origem, religião, condição física, social ou intelec- tual, o que implica no problema da gestão da diferença, compreendida, nessa perspectiva, como força e base do trabalho escolar (SANCHES; TEODORO, 2006) abrangendo variadas áreas de conhecimento.

Contudo, a realidade cotidiana nos mostra que essa gestão da diferença se pauta mais por fragilidades do que por avanços, ou, por discursos que, na verdade, reafirmam a exclusão, uma vez que esta se faz necessária para a manutenção do discurso de inclusão. Seria a própria negação da expressão inclusão - a exclusão -, o mecanismo que a permite existir. Antônio Osório e Tatiana Leão (2013) sustentam essa afirmativa ao analisarem, sob uma perspectiva foucaultiana, documentos que antecederam e resultaram na elaboração da Política Nacional de Educação Especial. Para este autor e esta autora:

[...] os discursos de inclusão, reforçados na última década, só podem ser analisados como um paradoxo, não se autoexplicam e se alinham a outras redes de discursos voltados para mudanças, superação das diferenças e dos conflitos, visando à outra ordem social. Passam a ser um campo minado, na medida em que as dimensões desses embates se localizam a partir das lutas de raça, associados ao gênero, à cor, ao uso do corpo como um todo e projetados às condições institucionais. Estas o reforçam, pelo conjunto ou isolados, das diferenças, provocando um défice social, produzido pelas práticas culturais (OSÓRIO; LEÃO, 2013, p. 687).

Nessa direção, não diferente das relações institucionais que organizam a sociedade, as prerrogativas de justiça social contidas no discurso de inclusão escolar consolidam, na maioria das vezes e em variadas dimensões, a seletividade social. 
Sob o discurso de respeito à diversidade, essas prerrogativas encobertam sutilmente as estratégias de controle social ao se pautarem em binarismos que separam os sujeitos em razão dos marcadores que os constituem (classe social, gênero, sexualidade, idade, deficiência, raça, etnia, etc.) e determinam os lugares e posições sociais a serem ocupados em detrimento dessas marcas, sendo, consequentemente, identificados, caracterizados, classificados e, por vias mais inusitadas, isolados. Esses mecanismos constituem os processos de vigilância, punição e disciplinamento dos corpos (OSÓRIO; LEÃO, 2013).

Para este estudo, a Educação Física escolar é nosso foco de atenção, interpretada através das vivências de pessoas que ultrapassam e/ou vivem nas fronteiras do gênero - travestis, transexuais e transgêneros -, sujeitos de uma pesquisa de doutorado em Educação realizada no período de 2010 a 2014.

A definição das identidades de gênero travesti, transexual e transgênero torna-se um processo complexo e que traz à contextualização uma série de discussões que envolvem aproximações e distanciamentos entre movimento social e meio acadêmico. Portanto, buscando uma mediação entre esses dois campos, sugiro a priori -, a descrição proposta por Willian Peres (2009, p. 236):

De modo bastante rápido, defino as travestis como pessoas que se identificam com a imagem e o estilo feminino, apropriando-se de indumentárias e adereços de sua estética, realizando com frequência a transformação de seus corpos, quer por meio da ingestão de hormônios, quer através de aplicação de silicone industrial e das cirurgias de correção estética e próteses. As transexuais são pessoas com demandas de cirurgias de mudança de sexo e de identidade civil, demandas que não encontramos nas reivindicações emancipatórias das travestis.

Sobre o conceito de transgênero, Peres (2009, p. 236) o propõe como uma categoria subsequente às travestis e os/as transexuais. Para ele são “[...] pessoas que se caracterizam esteticamente por orientação do gênero oposto não se mantendo o tempo todo nessa caracterização como fazem as travestis e as transexuais.", elenca como sujeitos que se aderem a este grupo as/os transformistas, as dragqueens, os dragkings e outros/as.

\section{TRAJETO TEÓRICO-METODOLÓGICO DA PESQUISA}

A pesquisa em pauta objetivou identificar e problematizar indícios de desestabilização que a presença de professoras trans provocaria nas escolas nas quais atuavam. A opção em identificar pessoas travestis, transexuais e/ou transgêneros como "trans" foi inspirado na expressão "universo trans", descrita por Marcos Benedetti (2005, p. 17), na tentativa de possibilitar a ampliação do leque de definições que abrange as "transformações do gênero" e as "personificações" de gênero polivalente, transformado e modificado.

Em consonância com este autor e subsidiado nas teorizações de Butler (2003), entende-se a tentativa de categorizações identitárias desses sujeitos, na maioria das vezes, como um processo equivocado e fadado ao fracasso. Assim, compreende-se o gênero como uma construção cultural 
negando que ele seja aparentemente fixo como o sexo ou um resultado casual definido por sua estrutura biológica, assim como se nega a possibilidade de compreender o sexo apenas como um dado da natureza ou do destino. Nessa perspectiva, sexo foi desde sempre gênero, matizado pelo discurso. Com isso, abre-se um espaço para pensar o gênero como a interpretação múltipla do sexo, ou ainda, os significados culturais assumidos pelos corpos sexuados, não decorrendo de um sexo propriamente dito, mas considerando que "[...] a distinção sexo/ gênero sugere uma descontinuidade radical entre corpos sexuados e gêneros culturalmente construídos." (BUTLER, 2003, p. 24).

A pesquisa se sustentou nos princípios da teoria queer por ancorar-se numa forma múltipla e dinâmica na proposição de problematizações dos campos identitários. Com isso, possibilita-nos visualizar, analisar e contextualizar o campo geral no qual todas as identidades, sexuais, gêneros, raciais, classes, são construídas, percebendo-as necessárias e inter-relacionadas, constituindo uma realidade complexa e em constante movimento nas mais variadas dimensões: históricas, sociais, políticas e educacionais, assim como descrito por Guacira Louro (2004).

Marcado por confusões, conflitos e incômodos tanto no campo identitário como no campo disciplinar, o termo queer sugere "uma expansão politicamente volátil' das categorizações identitárias que procura incluir as mais diversas formas de outsiders do sexo e do gênero. Com isso, Joshua Gamson (2007, p. 347) observa que "[...] a teoria queer e os estudos queer propõem um enfoque não tanto sobre populações específicas, mas sobre os processos de categorização sexual e sua desconstrução."
Assim, este campo teórico sugere o desafio da forma como compreendemos as categorias sexuais e de gênero.

Visando o seu sentido mais característico, Gamson (2007, p. 347) utiliza o termo queer "[...] como um marcador da instabilidade da identidade." Situa os sujeitos bissexuais e transgêneros - ao serem incluídos nas políticas queer e assumirem o status de dissidentes do sexo e do gênero - como sujeitos que mais representam esse 'desafiar e confundir' em razão da forma como transitam, transgridem ou permanecem na fronteira das sexualidades e do gênero.

Esse "desafiar" e "confundir" se aproximam das argumentações de Richard Miskolci (2012) ao ressaltar como aspecto definidor do movimento queer o questionamento do regime de verdade que se sustenta na divisão dos sujeitos sociais entre normais e anormais. Incorpora-se, assim, como proposta política a crítica radical aos regimes de normalização em que a disciplina e o controle norteiam e definem as relações sociais e as discussões sobre a concepção de poder. Com isso, o pensamento de Michael Foucault emerge como um dos eixos norteadores desse campo teórico, aspecto reafirmado por Louro (2004) ao lembrar como Foucault contribuiu de forma significativa para os estudos queer ao descrever a compreensão do sujeito como produzido por práticas discursivas e não discursivas de saber e de poder.

Considerando essas questões, nossas reflexões circundam o universo das teorias pós-críticas do conhecimento. Para Tomaz Tadeu da Silva (2007) esse campo sucedeu às teorias críticas cujo foco consiste na influência dos processos de dominação de classe subsidiados pela exploração 
econômica que se efetivaram como poderosas e insubstituíveis ferramentas de análise das sociedades de classes realizadas pela teoria marxista. Partilhando fundamentos epistemológicos elaborados pelas teorias críticas, as teorias pós-críticas assentiram ao campo de análise social outros processos de dominação tais como raça, etnia, gênero e sexualidades, oportunizando outras interpretações para os conceitos de alienação, emancipação, libertação e autonomia. Ampliam-se, como isso, as possibilidades de compreensão dos processos estabelecidos a partir das relações de poder e dominação que nos têm.constituído.historicamente.

Doze professoras trans de cinco regiões do país compuseram o universo investigado: duas da região sul, quatro da região sudeste, três da região centro-oeste, duas da região nordeste e uma da região norte; que, por meio de entrevista e questionários nos possibilitaram a construção do material empírico da investigação.

No ano de 2014, essas docentes se encontravam na faixa etária de vinte e sete a quarenta e seis anos. Sete delas se identificavam com a identidade de gênero transexual, quatro como travestis e uma como transgênero. A área de formação nas ciências humanas e sociais era predominante entre as professoras. A licenciatura em Letras foi o curso concluído por seis delas. A atuação em escolas da rede púbica de ensino foi uma das características marcantes do grupo. O tempo de experiência na docência formal variou de um a vinte e um anos. A atuação na Educação Básica constituiu uma experiência vivenciada por todos os sujeitos da pesquisa.

Ademais de entrevistas e questionário, a pesquisa se ancorou em análise de fontes bibliográficas e documentais e, no que se refere à relação universo trans e Educação Física, essa discussão veio à tona inspirada nas informações contidas no folder "A travesti e o[/a] educador[/a $]^{2 \text { " }}$ (BRASIL, 2004a) que apresenta demarcadores dos processos de exclusão de pessoas trans no contexto escolar.

\section{Demarcadores dos gêneros possíveis na escola}

Ressaltando o contexto educacional no sentido mais amplo - em que a Educação Física também se insere -, as teorias críticas do conhecimento influenciaram significativamente na criação de medidas governamentais que desencadeassem posturas educativas inclusivas. Nuances desse processo de inclusão vão se refletir na Educação brasileira por meio da proposta dos Parâmetros Curriculares Nacionais (PCN), publicados em 1997. Os PCN apresentam os "temas transversais" - ética, saúde, meio ambiente, orientação sexual e pluralidade cultural -, cujas concepções e objetivos devem atravessar ou serem contemplados no programa curricular de todas as áreas do conhecimento e em todas as séries/ciclos da Educação Básica (BRASIL, 2000).

2 De acordo com a abordagem teórico-metodológica subsidiada pelos Estudos de Gênero, a generalização de inferência a homens e mulheres pela utilização de expressos no masculino torna-se uma postura inadequada, insuficiente e combatida constantemente por estudiosos/as que se dedicam a esse campo de investigação. Em razão disso, ao longo do texto alterou-se a forma de apresentação do título do folder contemplando os dois gêneros, portanto, "A travesti e o[/a] educador [/a]", que na versão original contempla apenas o gênero masculino. 
Como iniciativa de incluir os/as "outros/as" dentro das relações educacionais, o volume 10 dos PCN, Pluralidade Cultural e Orientação Sexual, sugere que temáticas envolvendo raça e etnia, corpo, gênero e sexualidade sejam inseridas na Educação Básica com o intuito de reduzir os processos de segregação social que a permeiam. No entanto, em variados campos de investigação, constata-se que poucos efeitos foram desencadeados com a criação dos PCN, levando, anos depois, que os processos de inclusão escolar fossem norteados por aparatos legais mais diretivos e que obrigassem um olhar específico à singularidade dos/as "outros/as" na Educação.

Nesse trajeto, nos encaminhamentos no setor de políticas públicas que lutam pela garantia do reconhecimento das diferenças e à singularidade de pessoas trans encontramos planos, programas e projetos que apontam prerrogativas de inclusão para as demandas do segmento mais amplo de Lésbicas, Gays, Bissexuais e Trans (LGBT). Contudo, a Educação representa nessas políticas públicas uma das demandas voltadas para esse segmento e não a precursora dessas inquietações, o que justifica a maioria dessas políticas terem partido de iniciativas desenvolvidas pelo Ministério da Saúde, mais especificamente na perspectiva da prevenção às DST/Aids.

Dentre as propostas voltadas ao combate ao preconceito e discriminação à população LGBT vinculadas aos planos, programas e projetos, a primeira iniciativa específica para o segmento trans no campo educacional foi mobilizada pela campanha do Ministério da Saúde "Travesti e respeito: já está na hora dos dois serem vistos juntos. Em casa. Na boate. Na escola. No trabalho. Na vida." (BRASIL, 2004a, 2004b). A campanha foi elaborada com a participação de lideranças do movimento organizado de pessoas trans junto ao Programa Nacional de DST/Aids tendo como foco de atuação as escolas, os serviços de saúde, a comunidade e os/as clientes das travestis profissionais do sexo (BRASIL, 2004b).

Como descrito no site do Departamento de DST, Aids e Hepatites Virais (BRASIL, 2004b), cartazes, cartilhas e folders foram produzidos e parte do material ilustrados com fotos das vinte e sete trans que atuaram na elaboração da Campanha. Dois folders foram produzidos, um voltado aos/às profissionais da saúde e outro voltado aos/ às profissionais da Educação com o intuito de sensibilizá-los/as em relação aos maiores constrangimentos enfrentados por pessoas trans nesses espaços. Destinada à relação universo trans e Educação, o folder "A travesti e o[/a] educador[/a]: respeito também se aprende na escola." (figura 1) aborda de forma sucinta os principais aspectos que geram obstáculos para permanência de alunas/ os trans na escola, quais sejam: a questão do nome social, a utilização do banheiro, a adequação à prática da disciplina Educação Física e a associação de pais e mestres ${ }^{3}$.

3 Seguindo os mesmos parâmetros da Campanha "Travesti e respeito", o segmento organizado trans brasileiro, junto ao Departamento de DST, Aids e Hepatites Virais, lançaram em 2010 a Campanha "Sou travesti. Tenho o direito de ser quem eu sou." Nela, outro material visando o campo educacional foi produzido: o folder "Educação sem preconceitos: a travesti na escola." Destaca as mesma problemáticas do folder anterior, permanecendo, inclusive a generalização das expressões no masculino: professores, diretores, funcionário, educador, etc. No campo em que discorre sobre a aula de Educação Física acrescentou-se a expressão "transfobia", definida como "aversão às travestis" (BRASIL, 2010b). 
O segundo folder é voltado para o[/a] educador[a], lembrando que a exclusão social das travestis deve-se, fundamentalmente, ao abandono da escola, primeiro lugar onde elas encontram dificuldade de adaptação. As piadinhas maldosas dos colegas, a proibição de usarem os banheiros femininos e o desrespeito ao nome de mulher que adotam, entre outras atitudes preconceituosas, terminam por fazê-las desistir de estudar (BRASIL, 2004b, p. 1).

Esses aspectos foram destacados de forma significativa nos relatos das professoras investigadas tanto no processo de escolarização quanto na atuação docente no que se refere à vivência do preconceito e da discriminação em razão da forma como constroem seu gênero e vivem suas sexualidades. Por este motivo optamos problematizar os relatos das docentes utilizando dos demarcadores elencados no folder como parâmetros de análise. $\mathrm{O}$ fato de este folder ser o primeiro e único material que aborda exclusivamente a relação universo trans e Educação, mesmo que de forma breve, também justificou nossa opção em utilizá-lo como fonte de análise.
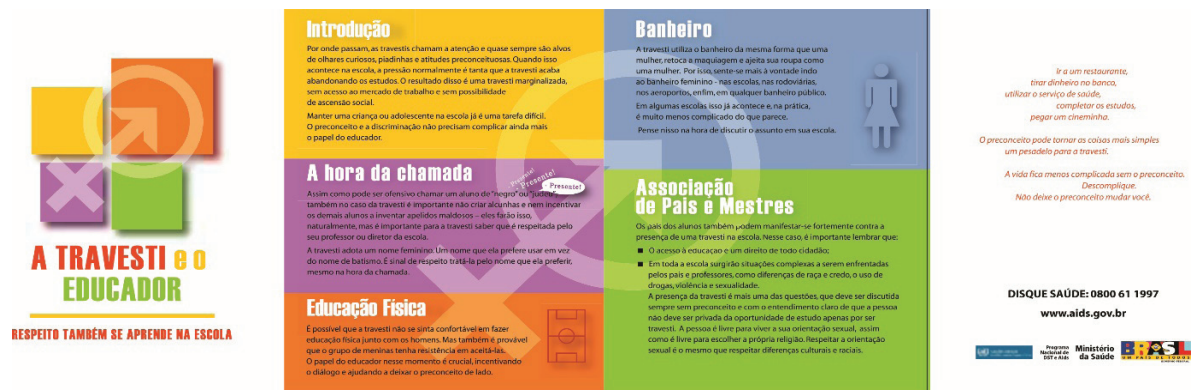

Figura 1: Folder A travesti e o[/a] educador[/a]

Fonte: Reproduzido do folder original impresso.

A questão do nome social e a utilização do banheiro foram os demarcadores mais segregadores destacados pelos sujeitos da pesquisa. Como exemplo, em 2008, após o implante de próteses nos seios e ampliar sua proximidade com o gênero feminino, Sayonara ${ }^{4}$ se recordou de seu retorno ao trabalho em uma das escolas que atuava. Segundo ela: "A diretora foi de porta em porta da escola e falou assim: 'O fulano, pôs peitos. Está vindo vestido de mulher.
Mas, deixamos bem claro que o nome dele continua [nome de registro masculino] ainda. Ele é o professor [nome de registro masculino]. '" (SAYONARA, UBERLÂNDIA-MG, OUTUBRO, 2011).

Sobre a utilização do banheiro, algumas professoras descreveram conflitos que antecediam a estruturação de suas identidades de gênero. Para Adry, esse espaço já representava um não lugar na Educação Infantil: "Eu me lembro do jardim de

4 Os nomes utilizados para identificação dos sujeitos correspondem aos seus nomes sociais ou civis - que foram alterados legalmente durante a investigação. Essa foi uma solicitação das professoras com o intuito de ampliar sua visibilidade social. Esse processo foi realizado mediante autorização assinada pelos sujeitos. 
infância. Tive que ir ao banheiro no recreio. Foi a coisa mais horrorosa da minha vida, porque só tinha que entrar no banheiro dos meninos. (...) Parecia que eu era um ser estranho ali. Não era ali o meu lugar." (Adry, Porto Alegre-RS, maio, 2013).

$\mathrm{Na}$ universidade, com sua identidade trans já constituída, a utilização do banheiro ainda gerava conflitos e incômodos:

Na faculdade eu já era Adriana e eu precisei ir ao banheiro. "E se aqueles homens me barrarem?" Eu ficava com receio. Não é? O afeminadinho. "Será que vão me barrar de ir ao banheiro feminino? E no banheiro masculino pode acontecer tanta coisa comigo." Já pensou? Tanto tempo eu ia ao masculino e sentia que não era o meu lugar. Por que não era. $\mathrm{E}$ eu tomei coragem e fui ao feminino. Só não me senti à vontade (Adry, Porto Alegre-RS, maio, 2013).

Outro aspecto interessante emergiu na discussão a respeito da associação de pais e mestres. Apesar de não ser o foco em questão, cabe destacar que enquanto o folder apresenta pais/mães como os/as principais desencadeadores/as de possíveis obstáculos para a presença de pessoas trans na escola, os relatos das docentes investigadas descreveram conflitos acirrados na relação com gestores e colegas de docência. Da mesma forma, o preconceito e a discriminação advindos de alunos/as foram aspectos de baixa recorrência. O relato de Adriana Sales abarca, no sentido mais amplo, o que foi argumentado pelas demais professoras colaboradoras da pesquisa sobre essa questão:

O meu posicionamento de me assumir travesti numa sociedade extremamente machista é algo complicado e o grande desafio foi lidar com os pares. E até hoje eles proporcionam problema de relacionamento na unidade escolar. Então, o maior conflito que esperamos que fosse com o alunado, com os pais, com a comunidade, e não é. O maior problema de uma travesti profissional da Educação na escola são os pares, os colegas. Os professores apresentam uma resistência muito grande (Adriana Sales, Cuiabá-MT, novembro, 2010).

Sobre a questão da aula de Educação Física, poucos elementos nos foram disponibilizados para essa análise em razão do período em que as professoras passaram pelo processo de transformação que, para a maioria, ocorreu durante ou após o Ensino Médio. Buscamos, contudo, também analisar como a disciplina Educação Física era interpretada legalmente na Educação Superior no período em que estiveram na universidade e como estabeleciam relações com essa área de conhecimento.

\section{A aula de educação física demarcando os gêneros possíveis}

Como descrito no folder "A travesti e o[/a] educador[/a]" (BRASIL, 2004a), adequar-se ao grupo masculino ou feminino na prática da disciplina Educação Física é um fator que dificultaria a inserção de pessoas trans na escola, em que o desconforto e a rejeição são dimensões que provavelmente serão desencadeadas nas práticas cotidianas dessa disciplina em razão da presença desses sujeitos.

De acordo com Helena Altmann, Eliana Ayoub e Silvia Amaral (2011) a divisão de grupos em razão do gênero nas aulas de Educação Física é uma postura que caiu 
em desuso desde a década de 1990. Essa se tornou uma prática quase inexistente nas escolas públicas brasileiras, especialmente, pelo fato de que atualmente somente um/a professor/a assume a responsabilidade de ministrar aula para toda turma.

A possibilidade de separá-los posteriormente, quando em quadra, para a realização de alguma atividade (ou todas) não deixou de existir, mas se tornou prerrogativa docente e não mais uma determinação legal. Assim, professores/ as de Educação Física passaram a ministrar aulas para meninos e meninas, enfrentando dilemas com essa nova organização escolar (ALTMANN; AYOUB; AMARAL, 2011, p. 495).

Nesse sentido, a interpretação do folder em relação à dinâmica da aula de Educação Física estaria mais voltada para uma "prerrogativa docente" na qual a presença da/o aluno/a trans seria outro dilema a ser enfrentado/a pelo/a professor/a. De acordo com o folder, há um papel crucial do/a docente no que se refere a estimular o diálogo e combater o preconceito (BRASIL, 2004a). Essa discussão nos remeteu a uma questão: Se a nova organização escolar criou o dilema a ser vencido pelo/a docente de Educação Física no que se refere a administrar as diferenças binárias de gênero num mesmo espaço, como seria o enfrentamento desse outro dilema no que se refere aos gêneros interpretados como fora da norma, ultrapassando e/ou em trânsito?

Em relação às docentes da pesquisa, interpretá-las dentro do universo da disciplina Educação Física tornou-se mais complicado em razão de a maioria ter concluído seu processo transformador na universidade ou na docência. Com isso, dentre elas, forneceram subsídios para essa análise Adriana Lohanna, Bruna e Sarah por terem passado pelo processo de transformação quando cursavam ainda a Educação Básica. Edna também contribuiu, pois no período em que cursou Letras entre 1993 a 1997, a prática da Educação Física ainda consistira de disciplina obrigatória no currículo da Educação Superior pública ${ }^{5}$. Para as demais docentes que iniciaram a transformação na universidade, seus cursos ou eram noturnos ou semipresencial. Nesses cursos, a dispensa consistia de direito pautado na Lei de Diretrizes e Bases da Educação (LDB) $\mathrm{n}^{\circ}$ 9.394/966 , ou, ainda, o período de graduação sobreveio quando a disciplina não era mais obrigatória (BRASIL, 2010a).

Bruna nunca vivenciou formas de violência na disciplina Educação Física. Informou que a partir da sétima série do Ensino Fundamental, contudo, solicitou dispensa da disciplina à direção da escola em que estudava e Ihe foi concedida. Sarah também era dispensada das aulas práticas de Educação Física permanecendo sempre

5 Sobre a prática da Educação Física na Educação Superior, Heber Paula e Elene Faria (1998) esclarecem que desde o parecer 376/97 oficializado pelo Conselho Nacional de Educação, sua presença nesse nível de ensino assumiu caráter facultativo, ficando a cargo de cada sistema de ensino decidir sobre sua inclusão ou não no currículo.

6 Para a LDB 9394/96 podem requerer o direito de dispensa da disciplina Educação Física aqueles/as que se enquadrem em: I - que cumpra jornada de trabalho igual ou superior a seis horas; II - maior de trinta anos de idade; III - que estiver prestando serviço militar inicial ou que, em situação similar, estiver obrigado à prática da Educação Física; IV - amparado pelo Decreto-Lei no 1.044, de 21 de outubro de 1969; V - (vetado); VI - que tenha prole (BRASIL, 2010a, p. 23). 
sentada observando as atividades realizadas pelos/as alunos/as de sua turma. Participava somente das aulas teóricas da disciplina. Nas poucas vezes que tentou participar das aulas, sua presença gerava muito estranhamento pela forma que sua feminilidade tornava-se mais evidenciada.

Com isso, Sarah era constantemente vítima de agressões verbais por parte dos alunos/as sendo exposta a várias formas de constrangimentos. Em certa ocasião, em razão desses constrangimentos e do tumulto que desencadeava nas aulas, um de seus professores de Educação Física disse a ela que não precisaria mais comparecer às aulas. Por outro lado, existia também por parte de Sarah uma resistência em participar das atividades físicas. Interpretava que essas práticas poderiam gerar aumento de sua massa muscular, enfatizando uma imagem corporal masculina, da qual tentava constantemente se distanciar.

Apoiado nos estudos de Tomas Laqueur (2001), identifica-se que no trajeto histórico da construção das masculinidades e das feminilidades uma série de processos hierárquicos foram estruturados e incorporados aos contextos sociais, definindo lugares específicos de homem e mulheres culturalmente. A concepção de virilidade, força, atitude e agressividade inerente ao masculino traduziu esse gênero como predominante nas relações de poder. Em razão de concepções biológicas primeiramente descritas na Antiguidade, mulheres sofrem historicamente atribuições como sendo seres incompletos (perspectiva falocêntrica), atribuindo a seus corpos pertenças relacionada à fragilidade, delicadeza, passividade e, sobretudo, submissão ao gênero prioritário.

No que se refere à Educação Física, Helena Altmann $(2015$, p. 31) ressalta as imagens divulgadas cotidianamente nos meios de comunicação e mercado de consumo como demarcadores e constituintes de corpos masculinos e femininos através de uma "pedagogia bastante sutil", acionada da forma distinta e desigual: "Imagens de uma menina dançando balé e de um menino jogando futebol, por exemplo, estabelecem uma relação entre uma prática corporal específica e o gênero; elas constituem campos de possibilidades corporais distintos a eles e elas."

Alfredo Veiga-Neto e Carlos Nogueira (2010) destacaram que o saber não é propriamente produzido pelo sujeito, estando, na verdade, o sujeito assujeitado ao saber; também sendo produzido por esse saber que determina as normas e as regras para construção dos discursos que devem pronunciar o próprio sujeito. A dispensa das aulas de Educação Física concebidas a Bruna e Sarah ressalta uma das formas pelas quais eram pronunciadas na escola: sujeitos inadequados à vivência das práticas corporais desenvolvidas naquele espaço.

Indícios dessa afirmativa emergem ao constatar que essas dispensas não foram relatadas pelos sujeitos como ancoradas no direito de dispensa das aulas de Educação Física descrito na LDB 9394/96 e, de forma mais latente no relato de Sarah, exaltava-se a forma como as marcas da feminilidade manifestadas pela via de seu corpo confrontavam e desajustavam a noção de sujeito moderno construída e ensinada histórica, social e culturalmente como permitida e correta.

Nesse caso, o sujeito se constitui dentro de uma rede sociocultural complexa na qual ocupa uma posição ou posições determinadas. Essa rede é tecida por fios, práticas discursivas e não discursivas, que por serem práticas são contingentes e, 
concomitantemente, mutáveis. No entanto, dentro de uma perspectiva arqueológica, ao constituir uma epistemologia na qual conceitos se fazem necessários para designar "entidades inventadas" que passam a assumir um caráter de naturalidade, o sujeito se define apenas como um efeito do saber. Isso acaba por impossibilitar a existência de um "sujeito-protagonista-porque-dono-de-um-saber", aspecto evidenciado por Veiga-Neto e Nogueira (2010) ao refletirem sobre os princípios da arqueologia do saber e suas inter-relações no campo educacional.

O alívio de Sarah pela dispensa das aulas ao interpretar que a prática da Educação Física demarcaria fisiologicamente as marcas da masculinidade em seu corpo reafirma a consagração das "entidades inventadas" (VEIGA-NETO; NOGUEIRA, 2010), uma vez que ressalta a hegemonia do gênero masculino associada à prática de atividades físicas. Sobre essa discussão, Louro (1997) comenta sobre o caráter militarista presente na história brasileira inicialmente evidenciada pela figura do bandeirante, símbolo de coragem, energia e, principalmente, elemento desencadeador do progresso nacional. Tal figura especificamente masculina e representação da virilidade é uma marca evidente na construção da estrutura escolar, sobretudo na disciplina Educação Física:

Se em algumas áreas escolares a constituição da identidade de gênero parece, muitas vezes, ser feita através dos discursos implícitos, nas aulas de Educação Física esse processo é, geralmente, mais explícito e evidente. Ainda que várias escolas e professores/as venham trabalhando em regime de co-educação, a Educação Física parece ser uma área onde as resistências ao trabalho integrado persistem, onde as resistências provavelmente se renovam, a partir de outras argumentações ou de novas teorizações (LOURO, 1997, p. 72-73).

Sob a perspectiva de Foucault (1995, p. 243), as instituições sociais exercem formas diferenciadas de relação de poder específicas e circunscritas a comunidade para qual se destina. Assim, relação de poder pode ser entendida como "[...] um modo de ação que não age direta e imediatamente sobre os outros, mas que age sobre sua própria ação. Uma ação sobre a ação, sobre ações eventuais, ou atuais, futuras ou presente." Em contrapartida, toda relação de poder desencadeia resistência ou "estratégias de confronto". Neste jogo, "[...] toda estratégia de confronto sonha em tornar-se relação de poder, e toda relação de poder inclina-se, tanto ao seguir sua própria linha de desenvolvimento quanto ao se deparar com resistências frontais, a tornar-se estratégia vencedora." (FOUCAULT, 1995, p. 248).

$\mathrm{Na}$ escola, a proposta de regime de co-educação pode ser interpretada como uma relação de poder, uma forma da ação sobre a ação do outro (do corpo docente), contudo, como descrito por Louro (1997), a disciplina Educação Física parece exercer uma força contrária, uma estratégia de confronto, uma recusa. Na concepção de Foucault (1995), a estruturação de um campo de batalha em que os princípios da co-educação tornam-se um alvo fixo, confrontado e em risco de ser colocado em suspensão. Esses aspectos reafirmam uma tênue linha que sustenta os limites entre relação de poder e estratégia de confronto, ou seja, uma depende da outra para suas existências.

Nas aulas de Educação Física Adriana Lohanna desencadeava estratégia de 
confronto contra a relação de poder responsável pela delimitação do masculino e do feminino. Neste jogo, apesar de sua resistência, era coagida por formas de violência verbal e física:

Teve um dia em que estava em uma aula de Educação Física e um menino me bateu: "Você tem que apanhar para virar homem. O que é isso? Você tem que virar homem!" Então, eu apanhei. Mas no Ensino Médio, isso acaba tomando uma amplitude maior, porque a gente assume uma condição de travesti, e aí a coisa é mais séria, porque você é mais vista (Adriana Lohanna, Aquidabã-SE, novembro, 2010).

Ao discutir a normatização de gênero na Educação Física escolar, Priscila Dornelles (2013) posicionou essa disciplina como conformadora dos sujeitos na contemporaneidade. Isso, no sentido de trazê-los e conduzi-los para os princípios de uma cultura dominante e hegemônica, na qual a "a condução da conduta do outro" se faz por meio de suas práticas educativas cotidianas. Ao agredir fisicamente Adriana sob a justificativa de que ela deveria "virar homem", o aluno possivelmente se empodera desses princípios da cultura elencado por Dornelles (2013), desencadeando, por meio da violência verbal e física, mecanismos para conduzir sua conduta para uma dimensão entendida hegemonicamente como correta. Com isso, Adriana era exposta ao que Dornelles (2013) definiu como um movimento demarcado por efeitos normativos que alicerçaram a noção de sujeito nas relações sociais pautadas em estratégias de poder. Isso faz com que sujeitos escolares que destoam dos padrões heteronormativos se tornem "(im)possíveis" e "(ir)reconhecíveis", com isso, a serem corrigidos.
Este "movimento demarcado por efeitos normativos" (DORNELLES, 2013) que emerge no relato de Adriana Lohanna ao referir-se sobre suas relações estabelecidas na escola foram evidenciados nos resultados da investigação de Ivan Junckes e Joseli Silva (2009, p. 164) ao concluírem que:

O resgate das experiências das travestis no espaço escolar evidencia que a escola tende a reproduzir o preconceito e a discriminação presentes na sociedade brasileira em relação às sexualidades consideradas fora das normas hegemônicas. Elas revelam outra versão do significado construído sobre o espaço escolar, tradicionalmente considerado um local protegido, onde são cultivadas as regras do respeito, da cidadania, da igualdade e do acesso universal ao conhecimento.

Ancorado teoricamente na "abordagem das pluralidades" como proposta da Nova Geografia Cultural e em estudiosos/ as vinculados/as às teorias pós-críticas, o estudo teve como objetivo refletir sobre as experiências de inclusão/exclusão de travestis na escola. O material empírico foi construído a partir da realização de entrevistas a treze travestis da cidade de Ponta Grossa no ano de 2007.

Para nossa investigação, um dos aspectos mais relevantes deste estudo foi o enfoque dado à relação de pessoas trans nas aulas de Educação Física - perspectiva investigativa ainda rara em estudos acadêmicos.

As aulas de educação física, na experiência das travestis, aparecem como momentos de dificuldades. Nesta disciplina, em que são testadas as habilidades dos corpos, a divisão clássica das modalidades esportivas é realizada por meio da polarização entre meninas 
e meninos. Esse momento, em que há uma imposição de linhas demarcatórias pelo professor[a], é relatado com grande angústia e aflição pelas travestis,[...] (JUNCKES; SILVA, 2009, p. 160).

As argumentações do autor e da autora potencializam a "prerrogativa docente" (ALTMANN; AYOUB; AMARAL, 2011) de separação dos gêneros nas aulas de Educação Física e, em especial, o processo de "renovação de resistências" (LOURO, 1997) apresentados linhas atrás. Mais expressivo se faz o relato de uma das travestis colaboradora da pesquisa supracitada, identificada no estudo como "Dayana":

Na educação física dava muita briga porque eu gostava de vôlei e eles queriam que eu jogasse futebol, e eu odiava futebol. E vôlei não dava porque o vôlei era para as meninas. Depois mudou, começou a ser mais misto, mas no começo não era assim. E eu odiava futebol, tinha que colocar shortinho curto, e eu tinha perninha roliça de mulher. Daí, gritavam alto: olha a gostosa, chuta a bola pro gol! Foi, a bicha foi pro gol! Eles ficavam narrando em voz alta só pra provocar e eu odiava aquilo. Nunca atendiam meu pedido de não querer jogar. Só na oitava série, tinha um professor que atendia tudo que eu pedia, mas era uma maricona safada que depois me cantava na hora da saída. Essa é que é a verdade! Ele tinha uns 40 e eu uns 14. (Dayana) (JUNCKES; SILVA, 2009, p. 160).

O relato da colaboradora da pesquisa de Junckes e Silva (2009), assim como o de Adriana Lohanna, destacam variadas formas de violências que representam o que Rogério Junqueira (2009a, 2009b, 2009c) definiu como "sinergia de vulnerabilidades" e "pedagogia do insulto". Para o autor, esses processos são norteadores das relações estabelecidas por pessoas LGBT no contexto escolar, afetando de maneira mais significativa o segmento trans por se consistir de um grupo ainda menos mobilizado politicamente em certas demandas sociais. Nessas relações, destacam-se principalmente contextos de humilhação, segregação, guetização e opressão aos quais são expostas, o que lhes vetam o acesso a direitos universais do ser humano, como a Educação. Neste sentido:

O espaço escolar aparece na vida das travestis como um local de treino para a vida em sociedade. Ao contrário do que a sociedade idealiza, a escola reproduz e reforça os padrões de exclusão que estão postos e naturalizados. Ela reforça as diferenças de renda, cor e gênero e educa para a reprodução dos padrões hegemônicos. (JUNCKES; SILVA, 2009, p. 159).

Para Edna, a experiência das aulas de Educação Física como trans foi vivenciada na Educação Superior, uma vez que era obrigatória naquele período. Não interpretou ter vivenciado constrangimentos, mas, narrou como criava estratégias para evitá-los. Sua escolha pela modalidade ginástica nos dois semestres em que cursou a disciplina foi uma dessas estratégias, cujas práticas, na maioria das vezes, consistiam de executar variações de corrida e ginástica aeróbica; além de consistir de um espaço prioritariamente ocupado pelo gênero feminino.

Comparecia às aulas trajando calça de moletom, camiseta larga e tênis com o intuito de esconder seu corpo - outra de suas estratégias. Relatou sobre o alívio das aulas terem sido ministradas por uma professora e o desconforto quando essa 
professora anunciava que a aula do dia seria na piscina: "Aí, era uma mulher, graças a Deus. No dia em que ela falava 'aula na piscina', eu olhava para ela... 'Não vai dar. Não vai dar não'. Ela olhava para mim e: 'Tudo bem, você não precisa entrar não.'" (Edna, Uberlândia-MG, maio de 20077).

Quando afirmou não ter vivenciado constrangimentos na prática da Educação Física na universidade, o discurso de Edna parece pouco atento a violência velada pela qual era sujeitada e que a conduzia a criação de estratégias de sobrevivência naquele espaço, pois, utilizava trajes com intuito de esconder seu corpo, o que não fazia quando frequentava ambientes não formais, como, por exemplo, as aulas de ginástica na academia: "[...] nunca coloquei sequer roupa de ginástica que eu uso para fazer ginástica na academia." (Edna, Uberlândia-MG, maio de 2007).

De certa forma, subsidiado nas argumentações de Tomaz Tadeu da Silva (1995), Edna estaria sendo interpelada como sujeito por um currículo cujo poder a produzia de forma particular por meio de práticas não discursivas, afinal, ninguém disse a ela que deveria se trajar daquela forma para ir às aulas. Essas práticas não discursivas possivelmente produziam um saber determinante de normas e regras que a pronunciavam como sujeito por meio de um discurso que evidenciava que ali não seria seu lugar para romper com as normas de gênero. Estava, assim, como relatou, por detrás dos trajes para esconder seu corpo e seu gênero dissidentes/queer (GAMSON,
2007). Neste processo, era assujeitada por um saber hegemônico e, como já descrito linhas atrás, contaminada por princípios constituintes da identidade social dos "arquitetos" da sociedade moderna responsáveis pela determinação das possibilidades de construção e existência do sujeito humano (VEIGA NETO; NOGUEIRA, 2010).

\section{CONSIDERAÇÕES}

O folder "A travesti e o[/a] Educador[/a]" é um aparato legal que lança um olhar específico sobre a questão de pessoas trans na escola, apesar de, como já dito, ser uma iniciativa vinculada ao Ministério da Saúde e que, como já constatado por outros estudos, sua inserção na escola é desconhecida e incipiente, ou, em outras palavras, inexpressiva aos interesses das políticas educacionais.

Acredita-se que os esforços políticos
realizados pelo governo brasileiro, em
conjunto com a sociedade civil, através
da implementação de importantes proje-
tos, apenas tangenciam transformações
no cotidiano escolar. Há resistências a
serem vencidas, desde a incorporação
dos temas transversais (raça, etnia, gê-
nero e sexualidade) nas disciplinas con-
vencionais, na atualização da linguagem
visual e escrita dos livros didáticos, até
a formação de professores capazes de
lidar com conflitos em torno da deflagra-
ção de atos discriminatórios contra pes-
soas que fogem da ordem heterossexual
(JUNCKES; SILVA, 2009, p. 164).

7 A problemática de investigação do doutorado surgiu de lacunas evidenciadas na pesquisa de mestrado realizada no período de 2007 a 2009 que destacou a construção da identidade docente de professores/as LGBT de uma cidade de Minas Gerais. Com isso, as histórias de vida de duas professoras trans foram acompanhadas desde 2007, quando relataram sobre suas vivências nas aulas de Educação Física. 
Corroborando com as argumentações acima, os relatos das professoras sobre suas vivências nas aulas de Educação Física destacam essa área de conhecimento como um dos vetores do preconceito e da discriminação em relação àqueles/as que não construíram seus gêneros e/ou vivem suas sexualidades dentro dos parâmetros hegemonicamente estabelecidos.

Se a escola consiste de um espaço em que processos de inclusão devam nortear suas práticas cotidianas, os sujeitos da pesquisa denunciam o fracasso dessa proposta. Seus relatos confirmam as argumentações de Berenice Bento (2008, p. 131) ao concluir que "[...] há um projeto social, uma engenharia de produção de corpos normais que extrapola os muros da escola, mas que encontrará neste espaço um terreno fértil de disseminação." Neste projeto social o artifício de exclusão social de pessoas trans acaba sendo anunciado e definido convenientemente como evasão escolar.

Sobre as aulas de Educação Física, as docentes delataram que essa exclusão se processava de diversas formas. Para Bruna e Sarah se configurou pela dispensa da prática dessa disciplina. Adriana Lohanna vivenciou nesse espaço situações de violência verbal e física que ao se remeter à direção da escola cobrando providências quanto ao fato, ouvia apenas que deveria se acostumar, sendo, de certa forma, culpabilizada pelas circunstâncias em razão de sua "escolha" ou "condição" de ser trans. No caso de Edna, o processo de violência se manifestava de forma sutil, uma vez que ela tentava ocultar seu corpo trans em trajes largos como forma de não causar impactos ou desconfortos nas aulas; o que mais se aproxima de uma postura de assujeitamento às normas vigentes (VEIGA-NETO; NOGUEIRA, 2010).
Esses aspectos são ressaltados por Alessandra Bohm (2009, p. 83) ao afirmar que:

A escola, tal qual como se organiza e se estrutura hoje, não é para as travestis ou para qualquer outro "monstro" que fuja às normas socialmente estabelecidas. As possíveis diferenças entre os sujeitos são vistas como desigualdades, quando não são vistas como uma agressão aos padrões heteronormativos, fazendo com que os assim chamados sujeitos 'normais' se sintam no direito de agredir, ofender, humilhar.

No trajeto da estruturação da Educação Física como área de conhecimento escolar, "monstros" (FOUCAULT, 2000) tem cruzado seu caminho e reafirmado outras novas fragilidades que, não diferente da escola como um todo, determina os lugares possíveis e impossíveis para a existência do sujeito humano. Como explicitado por Junckes e Silva (2009), essas práticas exaltam a incoerência entre a realidade do cotidiano educacional e as normativas que determinam a escola como gestora da inclusão.

Pautado nos relatos dos sujeitos investigados, as discussões aqui realizadas estabelecendo relações entre universo trans e Educação Física escolar mais se aproximam de uma provocação ou uma tentativa inicial de despertar o interesse por essa questão tão específica, uma vez que, a inserção e permanência de alunas/os trans na escola consiste de uma dinâmica bastante recente em nossa sociedade, portanto, com amplas perspectivas de olhares a serem contextualizadas nas discussões de gênero e Educação.

\section{REFERÊNCIAS}

ALTMANN, Helena; AYOUB, Helena; AMARAL, Silvia C. F. Gênero na 
prática docente em educação física: "meninas não gostam de suar, meninos são habilidosos ao jogar"? Estudos Feministas. Florianópolis, n. 19, v. 2, p. 491-501, mai./ago. 2011.

ALTMANN, Helena. Educação física escolar: relações de gênero em jogo. São Paulo: Cortez, 2015.

BENEDETTI, M. Toda Feita: o corpo e o gênero das travestis. Rio de Janeiro: Garamond, 2005.

BENTO, Berenice. Alves de Melo. O que é transexualidade. São Paulo: Brasiliense, 2008.

BOHM, Alessandra M. Os "monstros" e a escola: identidade e escolaridade de sujeitos travestis. 2009. 103f. Dissertação (Mestrado em Educação) - Programa de Pós-Graduação em Educação, Universidade Federal do Rio Grande do Sul, Porto Alegre: 2009. BRASIL. Lei no 9.394/96. Diretrizes e Bases da Educação Nacional. 5. ed. Brasília: Câmara dos Deputados, Coordenação edições Câmara, 2010a. Disponível em: http://portal.mec.gov.br/seed/arquivos/ pdf/tvescola/leis/lein9394.pdf. Acesso em 29 out. 2012.

. Ministério da Saúde. Departamento de DST, Aids e hepatites virais. A travesti e o educador: respeito também se aprende na escola. Brasília: PNDST/ Aids, 2004a. (folder da campanha Travesti e respeito: já está na hora dos dois serem vistos juntos. Em casa. $\mathrm{Na}$ boate. $\mathrm{Na}$ escola. No trabalho. $\mathrm{Na}$ vida.).

. Ministério da Saúde. Departamento de DST, Aids e hepatites virais. Travestis ganham campanha contra aids e preconceito. 2004b. Disponível em: <http://www.aids.gov.br/noticia/ travestis-ganham-campanha-contraaids-e-preconceito $>$. Acesso em 15 abr. 2014.

. Ministério da Saúde. Departamento de DST, Aids e hepatites virais. Educação sem preconceitos: a travesti na escola. Brasília: PNDST/Aids, 2010b. (folder da Campanha Sou travesti. Tenho o direito de ser quem eu sou.). Disponível em: <http://www.aids.gov.br/travestis > . Acesso em 05 ago. 2015.

. Orientação sexual. In: Ministério da Educação e do Desporto. Secretaria de Educação Fundamental. Parâmetros Curriculares Nacionais: pluralidade cultural e orientação sexual. Rio de Janeiro: DP\&A, 2000. v. 10, p. 107-161.

BUTLER, Judith P. Problemas de gênero: feminismo e subversão de identidade. Tradução de Renato Aguiar. Rio de Janeiro: Civilização Brasileira, 2003.

DORNELLES, Priscila Gomes. "Apoios ou agachamentos?": a normalização do gênero na educação física escolar. $36^{\mathrm{a}}$ Reunião Nacional da ANPED. 2013, Goiânia. Anais... Rio de Janeiro: Anped, 2013. CD ROM.

FOUCAULT, Michel. Os Anormais. Tradução Eduardo Brandão. São Paulo: Martins Fontes, 2000.

. O sujeito e o poder. In: RABINOW, Paul; DREYFUS, Hubert. Foucault uma trajetória filosófica: para além do estruturalismo e da hermenêutica. Rio de Janeiro: Forense, 1995. p. 231-249. (Apêndice 1).

GAMSON, Joshua. As sexualidades, a teoria queer e pesquisa qualitativa. In: DENZIN, Norman K.; LINCOLN, Yvonna S. et al. O planejamento da pesquisa qualitativa: teorias e 
abordagens. 2. ed. Trad. Sandra Regina Netz. Porto Alegre: Artmed, 2007. p. 345-362.

GOELLNER, Silvana Vilodre. A produção cultural do corpo. In: LOURO, Guacira Lopes; FELIPE, Jane; GOELLNER, Silvana $V$. (Org.). Corpo, gênero e sexualidade: um debate contemporâneo na educação. 2. ed. Petrópolis, R J: Vozes, 2003, p. 28-40.

JUNCKES, Ivan J.; SILVA, Joseli $M$. Espaço escolar e diversidade sexual: um desafio às políticas educacionais no brasil. Revista de Didáticas Específicas, Madrid, n. 1, p. 148-166, dez. 2009. Disponível em http:// www.didacticasespecificas.com/files/ download/1/revistas/publicacion 1 . pdf\#page $=149$. Acesso em 10 mar. 2015.

JUNQUEIRA, Rogério Diniz. Educação e homofobia: o reconhecimento da diversidade sexual para além do multiculturalismo. In:

Diversidade sexual na educação: problematizações sobre a homofobia nas escolas. Brasília: Ministério da Educação Secretaria de Educação Continuada, Alfabetização e Diversidade, UNESCO, 2009a. p. 367-444.

. Homofobia nas escolas: um problema de todos. In:

Diversidade sexual na educação: problematizações sobre a homofobia nas escolas. Brasília: Ministério da Educação, Secretaria de Educação Continuada, Alfabetização e Diversidade, UNESCO, 2009b. p. 13-52.

- Políticas de educação para a diversidade sexual: escola com lugar de direitos. In: LIONÇO, Tatiana; DINIZ, Débora. (Org.). Homofobia
\& educação: um desafio ao silêncio. Brasília, Ed. UnB, 2009c. p. 161-193. LAQUEUR, Tomas Walter. Inventado o sexo: corpo e gênero dos gregos a Freud. Trad. Vera Whately. Rio de Janeiro: Relume Dumará, 2001.

LOURO, Guacira Lopes. Um corpo estranho: ensaios sobre sexualidade e teoria queer. Belo Horizonte: América, 2004.

Gênero, sexualidade e educação: uma perspectiva pós-estruturalista. 5 . ed. Petrópolis, RJ: Vozes, 1997.

MISKOLCI, Richard. Teoria queer: um aprendizado pelas diferenças. 2. ed. rev. e aum. Belo Horizonte: UFOP (Universidade Federal de Ouro Preto), 2012.

OSÓRIO, Antônio. C. N.; LEÃO, Tatiana. C. L.. Diversidade e educação especial em diálogos: reflexões sobre os discursos da inclusão. Revista Educação Especial (UFSM), v. 26, p. 685-698, 2013. Disponível em: <http://cascavel. ufsm.br/revistas/ojs-2.2.2/index.php/ educacaoespecial/article/view/8269>. Acesso em 19 nov. 2015.

PAULA, Heber Eustáquio; FARIA, Elene Lopes. A educação física no terceiro grau: contexto atual e perspectivas. Pensar a prática. Goiânia, v. 1, n.1, 1998. Disponível em: <http://www. revistas.ufg.br/index.php/fef/article/ view/15/2618 > . Acesso em 05 nov. 2013.

PERES, William. Cenas de exclusões anunciadas: travestis, transexuais, transgêneros e a escola brasileira. In: JUNQUEIRA, Rogério Diniz. Diversidade sexual na educação: problematizações sobre a homofobia nas escolas. Brasília: Ministério da Educação, 
Secretaria de Educação Continuada, Alfabetização e Diversidade, UNESCO, 2009. p. 235-264.

SANCHES, Isabel; TEODORO, Antônio.

Da integração à inclusão escolar: cruzando perspectivas e conceitos.

Revista Lusófona de Educação, n. 8, 63-83, 2006.

SILVA, Tomaz Tadeu. Documentos de identidade: uma introdução às teorias do currículo. 2. ed. Belo Horizonte: Autêntica, 2007.

- Currículo e identidade social:

territórios contestados. In:
Alienígenas na sala de aula: uma introdução aos estudos culturais em educação. Petrópolis, RJ: Vozes, 1995. 190-207.

VEIGA-NETO, Alfredo; NOGUEIRA, Carlos Ernesto. Conhecimento e saber apontamentos para os estudos de currículo. In. SANTOS, L. L. et al (Org.). Convergências e tensões no campo da formação e do trabalho docente. Belo Horizonte: Autêntica, 2010, p. 67-87.

PHYSICAL EDUCATION AS A TERRITORY TO POSSIBLE GENDER ESTABLISHMENT: school experiences of transvestites, transexuals and transgender people

\section{ABSTRACT}

The Physical Education class at school interpreted through the experiences of the people who go beyond and/or live on the borders of gender is the focus of this study. It highlights considerations triggered by the analysis of the folder "A travesti e o[/a] educador[/a]" - about the insertion of these subjects in the Physical Education class -, correlated to bibliographic sources, interviews and questionnaires given to transvestite, transexuals and transgender brazilian teachers. It was concluded that, not unlike the school as a whole, Physical Education is also a space that exalts the incoherence between the reality of the educational routine and the norms that determine the school as a manager of inclusion.

Keywords: Trans Teachers; Transphobia; Physical Education; Gender 
LA EDUCACIÓN FÍSICA COMO TERRITORIO DE DEMARCACION DE LOS GÉNEROS POSIBLES: vivencias escolares de personas travestis, transexuais y transgéneros

\section{RESUMEN}

La Educación Física escolar interpretada a través de las vivencias de personas que ultrapasan y/o viven en las fronteras del género es el foco de este estudio. Destaca reflexiones desencadenadas por los análisis del folder "A travesti e o[/a] educador[/a]" - acerca de la inserción esos sujetos en la clase de Educación Física -, mesclado con fuentes bibliográficas, entrevistas realizadas y cuestionarios aplicados a la profesoras travestis, transexuais y transgéneros brasileñas. Se concluyó que, no diferente de la escuela em general, la Educación Física es también un espacio que exalta la incoerência entre la realidad del cotidiano educacional y las normativas que determinan la escuela como gestora de la inclusión.

Palabras clave: Profesoras Trans; Transfobia; Educación Física; Género

Recebido em: agosto/2015 Aprovado em: dezembro/2015 